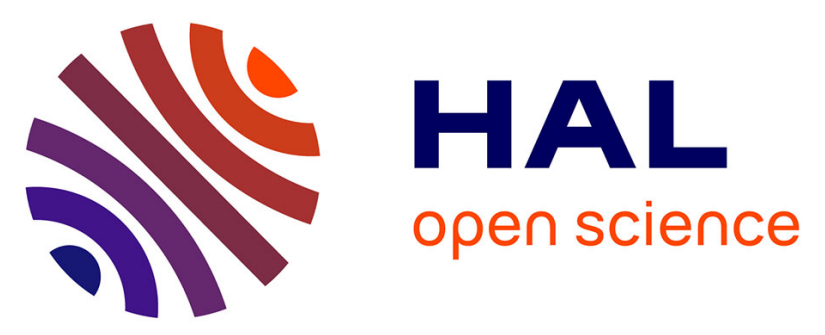

\title{
Tuning electronic structure through halide modulation of mesoionic carbene cobalt complexes
}

\author{
Alex J Mantanona, Daniel R Tolentino, Kristine S Cay, Milan Gembicky, \\ Rodolphe Jazzar, Guy Bertrand, Jeffrey D Rinehart
}

\section{To cite this version:}

Alex J Mantanona, Daniel R Tolentino, Kristine S Cay, Milan Gembicky, Rodolphe Jazzar, et al.. Tuning electronic structure through halide modulation of mesoionic carbene cobalt complexes. Dalton Transactions, 2020, 49 (8), pp.2426-2430. 10.1039/c9dt04624k . hal-03086591

\section{HAL Id: hal-03086591 https://hal.science/hal-03086591}

Submitted on 5 Nov 2021

HAL is a multi-disciplinary open access archive for the deposit and dissemination of scientific research documents, whether they are published or not. The documents may come from teaching and research institutions in France or abroad, or from public or private research centers.
L'archive ouverte pluridisciplinaire $\mathbf{H A L}$, est destinée au dépôt et à la diffusion de documents scientifiques de niveau recherche, publiés ou non, émanant des établissements d'enseignement et de recherche français ou étrangers, des laboratoires publics ou privés. 


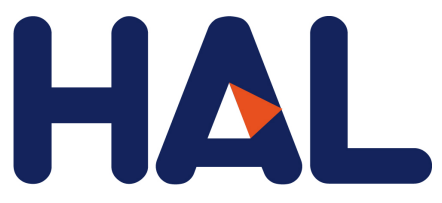

archives-ouvertes

\section{Tuning electronic structure through halide modulation of mesoionic carbene cobalt complexes}

Alex Mantanona, Daniel Tolentino, Kristine Cay, Milan Gembicky, Rodolphe Jazzar, Guy Bertrand, Jeffrey Rinehart

\section{To cite this version:}

Alex Mantanona, Daniel Tolentino, Kristine Cay, Milan Gembicky, Rodolphe Jazzar, et al.. Tuning electronic structure through halide modulation of mesoionic carbene cobalt complexes. Dalton Transactions, Royal Society of Chemistry, 2020, 49 (8), pp.2426-2430. 10.1039/c9dt04624k . hal-03086591

\section{HAL Id: hal-03086591 \\ https://hal.archives-ouvertes.fr/hal-03086591}

Submitted on 22 Dec 2020

HAL is a multi-disciplinary open access archive for the deposit and dissemination of scientific research documents, whether they are published or not. The documents may come from teaching and research institutions in France or abroad, or from public or private research centers.
L'archive ouverte pluridisciplinaire HAL, est destinée au dépôt et à la diffusion de documents scientifiques de niveau recherche, publiés ou non, émanant des établissements d'enseignement et de recherche français ou étrangers, des laboratoires publics ou privés. 


\section{Tuning electronic structure through halide modulation of mesoionic carbene cobalt complexes}

Received 00th January 20xx, Accepted 00th January 20xx DOI: $10.1039 / x 0 x \times 00000 x$

\author{
Alex J. Mantanona, Daniel R. Tolentino, Kristine S. Cay, Milan Gembicky, Rodolphe Jazzar, Guy \\ Bertrand, and Jeffrey D. Rinehart*
}

The first examples of $\mathrm{Co}$ (II) mesoionic carbene complexes ( $\left.\mathrm{CoX}_{2}{ }^{\text {Dipp }} \mathrm{MIC}_{2} ; \mathrm{X}=\mathrm{Cl}^{-}, \mathrm{Br}^{-}, \mathrm{I}^{-}\right)$demonstrate a new electronic perturbation on tetrahedral $\mathrm{Co}$ (II) complexes. Using absorption spectroscopy and magnetometry, the consequences of the MIC's strong $\sigma$-donating / minimal $\pi$-accepting nature are analyzed and shown to be further tunable by the nature of the coordinated halide.

Using ligand coordination to fine-tune the electronic structure of transition metals is a mature area of both organometallic and inorganic coordination chemistry. ${ }^{1}$ The discovery of distinctly new properties and reactivity, therefore, is often contingent upon the use of ligands that induce non-standard perturbations upon the metal center. An iconic example was the introduction of $\mathrm{N}$-heterocyclic carbene (NHC) ligands where strong $\sigma$ donation and wide steric tunability led to an explosion of newly accessible organometallic reactivity. NHC-ligated complexes with nearly every transition metal have been isolated to target luminescent, magnetic, catalytic, and a wide range of other properties. $^{2}$ In addition to NHCs, the electronic versatility of carbenes has diversified to include systems such as the strong $\sigma$ - and $\pi$-accepting cyclic alkyl-amino carbenes (CAACs) ${ }^{3}$ and the more purely $\sigma$-donating mesoionic carbenes (MICs) (Figure 1) ${ }^{4}$ 5 These variable electronic properties offer an intriguing and less explored contrast to the NHCs, especially for first-row transition metal complexes where only 36 such MIC complexes have been reported in the Cambridge Structural Database.

Amongst the transition metals, complexes of Co(II) provide some of the most diverse and interesting electronic structure behavior due to an inherent ground-state bistability from Kramer's degeneracy and relatively large spin-orbit coupling. ${ }^{7}$ Tetrahedrally-coordinated high-spin $\mathrm{Co}$ (II) is particularly intriguing from an electronic structure standpoint. While its ${ }^{4} \mathrm{~A}_{2}$ ground state has no first order orbital moment, it does have a wide variability in ligand-field strength, distortions in symmetry,

Department of Chemistry and Biochemistry, University of California - San Diego, La Jolla, CA 92093, USA.E-mail: jrinehart@ucsd.edu

Electronic Supplementary Information (ESI) available: CIF, synthetic details, and additional magnetic and crystallographic data. See DOI: 10.1039/x0xx00000x

and spin-orbit coupling that all contribute to a rich manifold of low-lying excited states. These provide a source of electronic structure tunability, opening up diverse applications from olefin oligomerization, ${ }^{7}$ electrocatalytic C-C bond formation, ${ }^{8}$ quantum sensing and computing, ${ }^{9}$ as well as molecular spintronics, ${ }^{10}$ and single-molecule magnetism (SMM). ${ }^{11-17}$

Despite intense interest in both Co(II) and MICs, there are no examples of structurally-characterized complexes combining this metal-ligand pair. In fact, only two MIC complexes with any Co oxidation state have been previously characterized, both being $\mathrm{Co}(\mathrm{III}) .{ }^{18}$ Additionally, while there have been a small number of reported SMMs containing carbenes in the literature, ${ }^{19-27}$ no comprehensive magnetic study on a series of simple metal halide carbenes of any type is available, nor have the magnetic properties of any MIC-containing compound been explored, leaving an invaluable characterization method for complex electronic structures untapped. To this end we synthesized and used a combination of optical absorbance spectroscopy and magnetometry to characterize a series of tetrahedral complexes comprising $\mathrm{CoX}_{2}{ }^{\text {Dipp }} \mathrm{MIC}_{2}\left(\mathrm{X}=\mathrm{Cl}^{-}, \mathbf{1} ; \mathrm{Br}^{-}\right.$, 2; and $\mathrm{I}^{-}$, 3) (Figure 2). In addition to the new information garnered about the Co(II)-MIC interaction, we demonstrate the further control over the magnetic anisotropy through the halide ligand, with an approximate doubling of the axial zero field splitting (ZFS) anisotropy constant $|D|$ between $\mathbf{1}$ and $\mathbf{3}$.

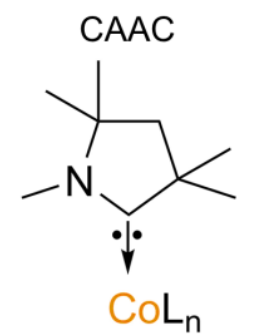

strong $\sigma$ donor strong $\pi$ acceptor Massard et al. (20)

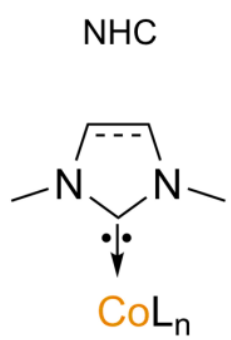

strong $\sigma$ donor mild $\pi$ acceptor Meng et al. (12)

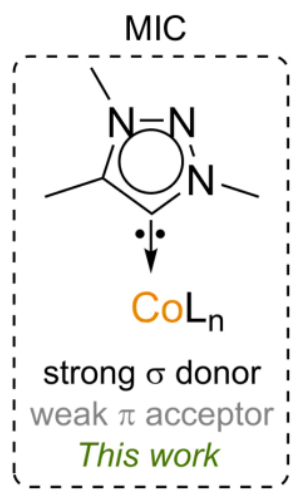

Figure 1: Cobalt complexes bearing carbenes with different donor and acceptor properties. Shown here are complexes containing (left) CAACs, (middle) NHCs, and (right) MICs. 


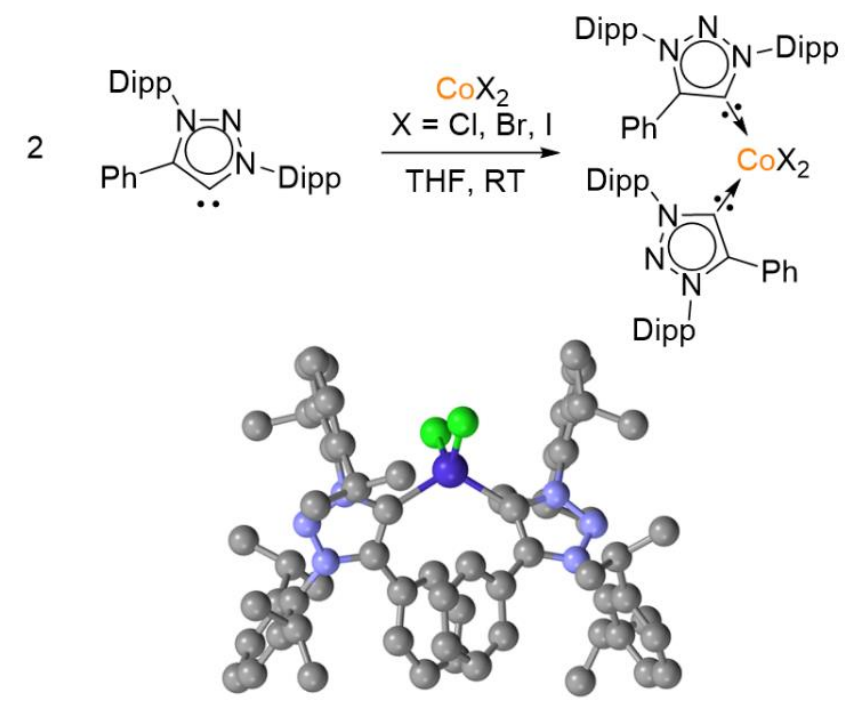

Figure 2: (Top) Reaction scheme for compounds 1-3. (Bottom) Crystal structure of 1 with spheres representing C (gray), Co (dark blue), $\mathrm{N}$ (light blue), and $\mathrm{Cl}$ (green). Hydrogen atoms have been omitted for clarity

Compounds 1-3 were obtained in good yield by treatment of a THF solution of the free MIC with the corresponding divalent cobalt halogen precursors $\left(\mathrm{CoX}_{2}, \mathrm{X}=\mathrm{Cl}^{-}, \mathrm{Br}^{-}, \mathrm{I}^{-}\right.$; Figure 2). The structures of 1-3 were confirmed by $\mathrm{X}$-ray crystallography and elemental analysis. As expected, in the solid-state, all three complexes have similar coordination environments although they crystallized in distinct space groups $\left(P \overline{\mathbf{1}}, P 2_{1} / \mathrm{n}\right.$, and $P c c n$ respectively). Select bond angles and distances between the cobalt center and ligands are tabulated in Table S1. The Co coordination environment in all three complexes are distorted tetrahedra with approximate $\mathrm{C}_{2 \mathrm{v}}$ symmetry. The phenyl substituents are arranged with parallel faces, which can be attributed to $\pi$-stacking interactions. Cobalt-carbene distances are comparable to bis-NHC bis-halide Co(II) complexes. ${ }^{28-29}$ The angular distortion from ideal tetrahedral geometry was calculated using an angular distortion parameter:

$$
\begin{gathered}
\tau_{\delta}=\frac{360-(\alpha+\beta)}{141} \delta \\
\delta=\frac{\beta}{\alpha}
\end{gathered}
$$

where $\alpha$ and $\beta$ define the largest and second largest L-Co-L angles. ${ }^{30}$ All three structures are remarkably similar in terms of total distortion from ideal tetrahedral geometry, with $\tau_{\delta}$ values of 0.89 being found for all three structures.

Variable temperature magnetic susceptibility $(T=1.8-300$ $\mathrm{K})$ and variable field $(H=-7-7 \mathrm{~T}) \mathrm{DC}$ magnetometry data were collected and fit simultaneously using an effective spin Hamiltonian with axial zero field splitting (ZFS) and Zeeman contributions (Equation 3). Only the absolute value of the axial ZFS constant is reported due to ambiguity in determining the sign via magnetometry. The value of $g$ is fit isotropically to minimize parameterization.

$$
\widehat{H}=D \widehat{S}_{z}^{2}+g_{\text {iso }} \mu_{B} S \cdot B
$$

Values of $|D|=6.54 \pm 0.02,8.53 \pm 0.01$, and $9.26 \pm 0.09 \mathrm{~cm}^{-1}$ and $g=2.24,2.26$, and 2.36, were obtained for $\mathbf{1}, \mathbf{2}$ and $\mathbf{3}$ respectively. Samples $\mathbf{2}$ and $\mathbf{3}$ displayed obvious signs of temperature independent paramagnetism (TIP) consistent with a susceptibility contribution unaffected by the Boltzmann population. To account for this, empirical values of $\chi_{\text {TIP }}=0.0001$, 0.0007 , and $0.0007 \mathrm{~cm}^{3} \mathrm{~mol}^{-1}$ were employed for 1, 2 and 3, respectively, similar in magnitude to other four-coordinate Co complexes reported in the literature. ${ }^{31}$ Although there are no direct comparisons for the ZFS values available in the literature for bis-carbene bis-halide Co(II) complexes, these values are within the range of reported values for bis-carbene two coordinate $\mathrm{Co}(\mathrm{I})$ complexes $\left(D=-8.2,-0.11\right.$, and $\left.33.4 \mathrm{~cm}^{-1}\right)$, and two and three coordinate isoelectronic $\mathrm{Fe}(\mathrm{I})$ complexes $(D=$ $\left.19.8,-13.6 \mathrm{~cm}^{-1}\right) .{ }^{19,} 23$ It is interesting that these axial $D$-values approach the magnitude of lower-coordinate systems, as typically lower-coordination of similar complexes leads to higher $D$-values due to smaller crystal fields.

Complexes 1, 2 and $\mathbf{3}$ display room temperature $\chi_{\mathrm{M}} T$ values of $2.37,2.63$ and $2.79 \mathrm{~cm}^{3} \mathrm{~mol}^{-1} \mathrm{~K}$, respectively (Figure 3 ). The value of $\chi_{\mathrm{M}} T$ down to $\sim 25 \mathrm{~K}$ is largely independent of temperature, especially for $\mathbf{1}$ while $\mathbf{2}$ and $\mathbf{3}$ show large contributions from TIP. At lower temperatures, the drop accelerates to reach $\chi_{\mathrm{M}} T \approx 1.6 \mathrm{~cm}^{3} \mathrm{~mol}^{-1} \mathrm{~K}$ for each compound. The room-temperature values are significantly larger than the spin-only value for a tetrahedrally coordinated $d^{7}$ metal with $S$ $=3 / 2$, suggesting a large second-order orbital contribution. This contribution is a manifestation of mixing excited states into ground states, with lower-field ligands (i.e. $\mathrm{Cl}^{-}>\mathrm{Br}^{-}>\mathrm{I}^{-}$) bringing excited states closer in energy to the ground state. The room-temperature magnetic susceptibilities of these compounds are larger than their bis-NHC, bis-halide Co counterparts, $^{32}$ while being slightly less than previously reported two- and three-coordinate $\mathrm{Co}(\mathrm{II})$ and isoelectronic $\mathrm{Fe}(\mathrm{I})$ carbene-based SMMs. ${ }^{21,} 23$

The tuning effect induced by the halide series was also apparent in spectroscopic data. Normalized to max intensity, UV/Vis/near-IR absorption data (Figure 4) show two distinct regions of excited energy states ranging from roughly 18,000 13,000 and $11,000-5,500 \mathrm{~cm}^{-1}$, in close agreement with reported bis-NHC bis-halide $\mathrm{Co}(\mathrm{II})$ complexes. ${ }^{28}$ These regions correspond to the transitions of the tetrahedral ${ }^{4} \mathrm{~A}_{2}\left({ }^{4} \mathrm{~F}\right)$ ground state to the excited ${ }^{4} \mathrm{~T}_{1}\left({ }^{4} \mathrm{~F}\right)$ and ${ }^{4} \mathrm{~T}_{1}\left({ }^{4} \mathrm{P}\right)$ states, with the ${ }^{4} \mathrm{~A}_{2}\left({ }^{4} \mathrm{~F}\right)$ $\rightarrow{ }^{4} \mathrm{~T}_{2}\left({ }^{4} \mathrm{~F}\right)$ transition outside of our measurement window. ${ }^{33}$ The spectra of the complexes show a clear red-shift with increasing

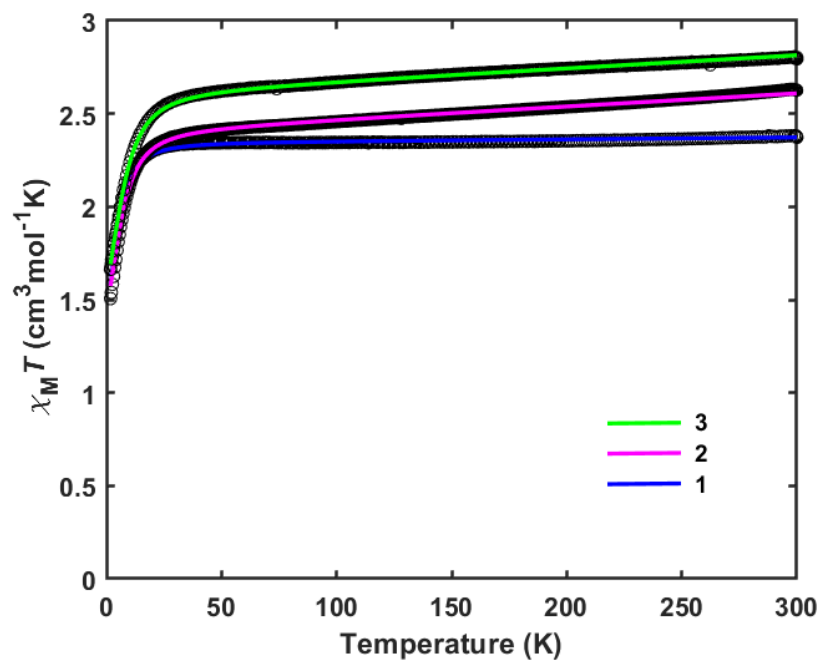

Fig 3: Product of susceptibility and temperature vs temperature of 1-3 as well as their fits using the effective spin Hamiltonian defined in Eq. 3. 


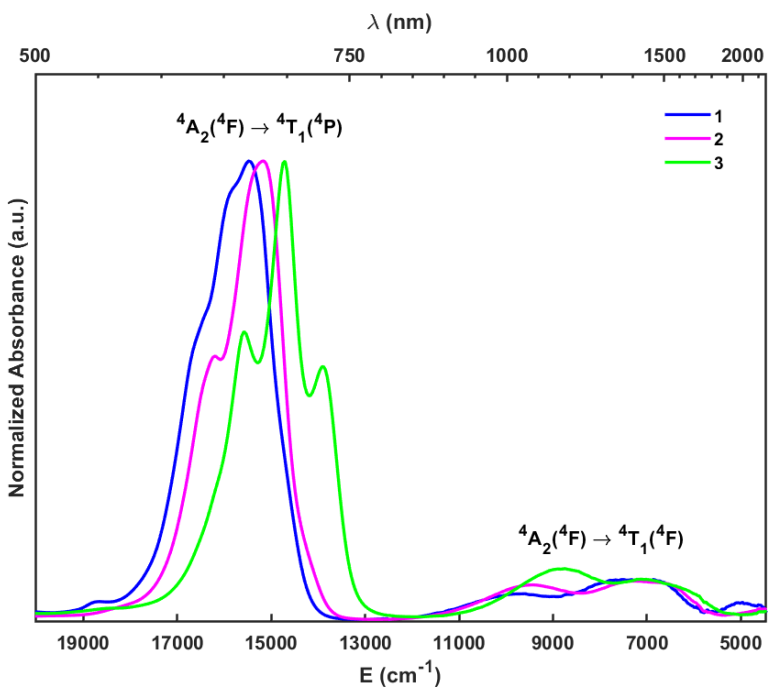

Figure 4: Normalized absorbance data for compounds 1-3 in THF showing red shifts as halide size increases

halide size for both regions, which can be attributed to the lower ligand-field strength of the heavier halides. Both regions for all three complexes contain multiple features resulting from spin-orbit coupling and splitting of the parent tetrahedral geometry to $C_{2 v}$ symmetry, which splits the ${ }^{4} T_{1}$ states into their ${ }^{4} A_{1},{ }^{4} B_{2}$, and ${ }^{4} B_{1}$ components. ${ }^{34}$ To quantify the ligand field Tanabe-Sugano diagrams were used to calculate $D q$ values..$^{35}$ Using the median energy value from the two excitation ranges in the absorption data to approximate a non-distorted tetrahedral excitation, $D q$ and B were calculated as $D q=394$, 387 , and $367 \mathrm{~cm}^{-1}$ and $B=635,615$, and $571 \mathrm{~cm}^{-1}$ for complexes 1-3, respectively. These values are slightly larger than their phosphine-halide analogs, indicative of stronger $\sigma$-donation of the MIC ligands. ${ }^{36}$

The ligand field of the complex plays a critical role in the lowlying energy states caused by ZFS. The two components contributing to ZFS are the minor direct spin-spin interactions and the dominant second-order spin-orbit coupling (SOC) introduced by mixing of ground and excited states. ${ }^{37}$ Computational $^{31,38}$ and experimental ${ }^{39-43}$ works have shown how anisotropy can be influenced via heavy atom coordination with further corroboration for ligand influence on ZFS in tetrahedral Co halide complexes emerging over the past five years. ${ }^{14,}$ 40-45 Complexes 1-3 show a clear trend in their $|D|$ values consistent with the expected electronic-structure effect. Specifically, we can attribute this trend to three effects: (1) Ligand-field strength correlates inversely with halide size, bringing the Co excited-states lower in energy for larger halides (Figure 4). This decreased ligand-field strength allows more mixing between Co states, which incorporates more SOC into the ground state. (2) Covalency in halides increases with halide size, yielding a larger contribution of ligand character to the molecular orbitals. (3) Relativistic effects in the larger halides allow for greater SOC, an effect that is enhanced due to the increased covalency and mixed states.

In summary, we present the first synthesis and electronicstructure analysis of Co(II)-MIC complexes. These compounds show clear correlations between halide size, excited-state energies, and ZFS. Analysis of magnetic and spectroscopic data revealed the ability of ligands to incorporate varying levels of second-order SOC into the metal center itself. The synthesis of these complexes paves the way for further studies on Co-MIC complexes to probe carbene effects on low-coordination environments. Now that a baseline for understanding changes in axial anisotropy in carbene-containing compounds has been set, future work will focus on making direct comparisons between MIC complexes and their NHC/CAAC counterparts. Expanding upon these trends will allow targeted development of systems that exploit the unique nature of the MIC ligand to control electronic and magnetic structure.

This research was funded through the National Science Foundation Division of Materials award \#DMR-1904937. We also thank Prof. Arnold Rheingold, Dr. Curtis Moore and Dr. Milan Gembicky at UCSD Crystallography for their expert crystallographic assistance.

\section{Conflicts of interest}

There are no conflicts to declare.

\section{References}

1 R. H. Crabtree, The organometallic chemistry of the transition metals, John Wiley \& Sons, 2009.

2 M. N. Hopkinson, C. Richter, M. Schedler and F. Glorius, Nature, 2014, 510, 485-496.

3 M. Melaimi, R. Jazzar, M. Soleilhavoup and G. Bertrand, Angew. Chem. Int. Ed., 2017, 56, 10046-10068

4 R. H. Crabtree, Coord. Chem. Rev., 2013, 257, 755-766.

5 M. Murrie, Chem. Soc. Rev., 2010, 39, 1986-1995.

6 a) G. Guisado-Barrios, M. Soleilhavoup and G. Bertrand, Acc. Chem. Res., 2018, 51, 3236-3244 b) A. Vivancos, C. Segarra, and M. Albrecht, Chem. Rev. 2018, 118, 9493-9586

7 C. Bianchini, G. Mantovani, A. Meli, F. Migliacci and F. Laschi, Organometallics, 2003, 22, 2545-2547.

8 M. van der Meer, Y. Rechkemmer, I. Peremykin, S. Hohloch, J. van Slageren and B. Sarkar, Chem. Commun., 2014, 50, 11104-11106.

9 M. S. Fataftah, S. C. Coste, B. Vlaisavljevich, J. M. Zadrozny and D. E. Freedman, Chem. Sci, 2016, 7, 6160-6166.

10 B. Sieklucka and D. Pinkowicz, Molecular magnetic materials: concepts and applications, John Wiley \& Sons, 2017.

11 Y. Rechkemmer, F. D. Breitgoff, M. Van Der Meer, M. Atanasov, M. Hakl, M. Orlita, P. Neugebauer, F. Neese, B. Sarkar and J. Van Slageren, Nat. Commun. 2016, 7, 10467.

12 M. S. Fataftah, J. M. Zadrozny, D. M. Rogers and D. E. Freedman, Inorg. Chem., 2014, 53, 10716-10721.

13 J. M. Zadrozny, J. Telser and J. R. Long, Polyhedron, 2013, 64, 209-217.

14 M. R. Saber and K. R. Dunbar, Chem. Commun., 2014, 50, 12266-12269.

15 M. Šebová, V. Jorík, J. Moncol', J. Kožíšek and R. Boča, Polyhedron, 2011, 30, 1163-1170.

16 S. Gómez-Coca, A. Urtizberea, E. Cremades, P. J. Alonso, A. Camón, E. Ruiz and F. Luis, Nat. Commun., 2014, 5, 4300.

17 E. Carl, S. Demeshko, F. Meyer and D. Stalke, Chem.:Eur. J., 2015, 21, 10109-10115.

18 M. van der Meer, E. Glais, I. Siewert and B. Sarkar, Angew. Chem. Int. Ed., 2015, 54, 13792-13795.

19 Y.-S. Meng, Z. Mo, B.-W. Wang, Y.-Q. Zhang, L. Deng and S. Gao, Chem. Sci. 2015, 6, 7156-7162.

20 R. C. Poulten, M. J. Page, A. G. Algarra, J. J. Le Roy, I. López, E. Carter, A. Llobet, S. A. Macgregor, M. F. Mahon, D. M. Murphy, M. Murugesu and M. K. Whittlesey, J. Am. Chem. Soc., 2013, 135, 13640-13643. 
21 X.-N. Yao, J.-Z. Du, Y.-Q. Zhang, X.-B. Leng, M.-W. Yang, S.-D. Jiang, Z.-X. Wang, Z.-W. Ouyang, L. Deng, B.-W. Wang and S. Gao, J. Am. Chem. Soc., 2017, 139, 373-380.

22 C. B K. C. Mondal, P. P. Samuel, H. W. Roesky, E. Carl, R. Herbst-Irmer, D. Stalke, B. Schwederski, W. Kaim, L. Ungur, L. F. Chibotaru, M. Hermann and G. Frenking, J. Am. Chem. Soc., 2014, 136, 1770-1773.

23 P. P. Samuel, K. C. Mondal, N. Amin Sk, H. W. Roesky, E. Carl, R. Neufeld, D. Stalke, S. Demeshko, F. Meyer, L. Ungur, L. F. Chibotaru, J. Christian, V. Ramachandran, J. van Tol and N. S. Dalal, J. Am. Chem. Soc., 2014, 136, 11964-11971.

24 P. P. Samuel, K. C. Mondal, H. W. Roesky, M. Hermann, G. Frenking, S. Demeshko, F. Meyer, A. C. Stückl, J. H. Christian and N. S. Dalal, Angew. Chem. Int. Ed., 2013, 52, 1181711821.

25 P. P. Samuel, R. Neufeld, K. Chandra Mondal, H. W. Roesky, R. Herbst-Irmer, D. Stalke, S. Demeshko, F. Meyer, V. C. Rojisha, S. De, P. Parameswaran, A. C. Stückl, W. Kaim, J. H. Christian, J. K. Bindra and N. S. Dalal, Chem. Sci., 2015, 6, 3148-3153.

26 U. Chakraborty, S. Demeshko, F. Meyer, C. Rebreyend, B. de Bruin, M. Atanasov, F. Neese, B. Mühldorf and R. Wolf, Angew. Chem. Int. Ed., 2017, 56, 7995-7999.

27 A. Massard, P. Braunstein, A. A. Danopoulos, S. Choua and P. Rabu, Organometallics, 2015, 34, 2429-2438.

28 T. E. lannuzzi, Y. Gao, T. M. Baker, L. Deng and M. L. Neidig, Dalton Transactions, 2017, 46, 13290-13299.

29 J. A. Przyojski, H. D. Arman and Z. J. Tonzetich, Organometallics, 2013, 32, 723-732.

30 M. H. Reineke, M. D. Sampson, A. L. Rheingold, and C. P. Kubiak, Inorg. Chem., 2015, 54, 3211-3217

31 E. A. Suturina, D. Maganas, E. Bill, M. Atanasov, and F. Neese, Inorg. Chem., 2015, 54, 9948-9961

32 R. S. Ghadwal, J.-H. Lamm, D. Rottschäfer, C. J. Schürmann and S. Demeshko, Dalton Trans., 2017, 46, 7664-7667.

33 J. Krzystek, S. A. Zvyagin, A. Ozarowski, A. T. Fiedler, T. C. Brunold and J. Telser, J. Am. Chem. Soc., 2004, 126, 21482155.

34 A. B. P. Lever, J. Chem. Educ., 1968, 45, 711.

35 H. Kato and K. Akimoto, J. Am. Chem. Soc., 1974, 96, 13511357.

36 C. Simo and S. Holt, Inorg. Chem., 1968, 7, 2655-2657.

37 S. Zein, C. Duboc, W. Lubitz and F. Neese, Inorg. Chem., 2008, 47, 134-142.

38 S. Ye and F. Neese, J. Chem. Theory and Comput., 2012, 8, 2344-2351

39 H. I. Karunadasa, K. D. Arquero, L. A. Berben and J. R. Long, Inorg. Chem., 2010, 49, 4738-4740.

40 D. Brazzolotto, M. Gennari, S. Yu, J. Pécaut, M. Rouzières, R. Clérac, M. Orio and C. Duboc, Chem.: Eur. J., 2016, 22, 925933.

41 L. Smolko, J. Černák, J. Kuchár, C. Rajnák, J. Titiš and R. Boča, Eur. J. Inorg. Chem., 2017, 2017, 3080-3086.

42 S. Vaidya, S. K. Singh, P. Shukla, K. Ansari, G. Rajaraman and M. Shanmugam, Chem.: Eur. J., 2017, 23, 9546-9559.

43 D. V. Korchagin, G. V. Shilov, S. M. Aldoshin, R. B. Morgunov, A. D. Talantsev and E. A. Yureva, Polyhedron, 2015, 102, 147151.

44 J.-J. Liu, Y.-S. Meng, I. Hlavička, M. Orlita, S.-D. Jiang, B.-W. Wang and S. Gao, Dalton Trans., 2017, 46, 7408-7411.

45 A. K. Mondal, M. Sundararajan and S. Konar, Dalton Trans. 2018, 47, 3745-3754. Note: References 44-50 refer to the experimental and methods section. For more details see Supplemental Info

46 A. B. Pangborn, M. A. Giardello, R. H. Grubbs, R. K. Rosen and F. J. Timmers, Organometallics, 1996, 15, 1518-1520.

47 O. V. Dolomanov, L. J. Bourhis, R. J. Gildea, J. A. K. Howard and H. Puschmann, J. Appl. Crystallogr., 2009, 42, 339-341.
48 G. Sheldrick, Acta Crystallogr. A, 2015, 71, 3-8.

49 G. Sheldrick, Acta Crystallogr. C, 2015, 71, 3-8.

50 G. A. Bain and J. F. Berry, J. Chem. Educ., 2008, 85, 532.

51 N. F. Chilton, R. P. Anderson, L. D. Turner, A. Soncini and K. S. Murray, J. Comput. Chem., 2013, 34, 1164-1175.

52 J. Bouffard, B. K. Keitz, R. Tonner, G. Guisado-Barrios, G. Frenking, R. H. Grubbs and G. Bertrand, Organometallics, 2011, 30, 2617-2627. 